Check for updates

Cite this: RSC Adv., 2019, 9, 19114

Received 25th March 2019 Accepted 3rd June 2019

DOI: 10.1039/c9ra02265a

rsc.li/rsc-advances

\title{
Non-covalent loading of ionic liquid-functionalized nanoparticles for bovine serum albumin: experiments and theoretical analysis $\uparrow$
}

\begin{abstract}
Xingang Jia, ${ }^{\text {ab }}$ Xiaoling Hu, (D) *a Wenzhen Wang ${ }^{\mathrm{b}}$ and Chunbao Du (D) ${ }^{\mathrm{b}}$
Biomacromolecule-based nanomaterials have attracted much attention due to their excellent function in sensing, catalysis, medicine, biology and recognition. In this work, a silane-coupling ionic liquid, 1-(3trimethoxysily(propyl)-3-methylimidazolium chloride ([TMIM]Cl), was synthesized and applied to prepare ionic liquid-functionalized nanoparticles $\left(\mathrm{SiO}_{2} \mathrm{QIL}\right)$ using surface grafting technology. By employing multiple non-covalent interactions, including electrostatic interactions, hydrogen bonding and $\pi-\pi$ stacking, the obtained functional nanoparticles were able to bind bovine serum albumin (BSA) with strong binding affinity, which has been illustrated through experiments and theoretical calculations. Moreover, the stability of $\mathrm{SiO}_{2} \mathrm{Q} / \mathrm{L}$ further demonstrated that it is promising in applications for biomacromolecule immobilization.
\end{abstract}

\section{Introduction}

Biomacromolecules, a promising molecular recognition vehicle, have received extensive attention owing to their precise sites, exceptional functionality and easily degradable properties. ${ }^{\mathbf{1 - 4}}$ Due to their superior biocompatible properties, different types of biomacromolecules, such as DNA, peptides, proteins, enzymes, viruses, etc., have been integrated with nano-based materials, and the fabricated nanomaterialbiomacromolecules have been used in extensive applications in materials science, nanotechnology and biomedicine..$^{5-10}$ Proteins are an important building block in organisms, for genetic information storage and transfer, and this has been utilized in combination with nano-based materials to create many functional nanomaterials. ${ }^{11-14}$ Silica $\left(\mathrm{SiO}_{2}\right)$ nanoparticles are one of the most commonly used nanomaterials in the biological field due to their favorable biocompatibility, and they have been applied to many areas of protein research. ${ }^{15-17}$ However, at present, there are still many challenges in constructing functional $\mathrm{SiO}_{2}$ for the immobilization of protein; for example, monotonous groups or chains grafted onto the surface of $\mathrm{SiO}_{2}$ can result in defects of unstable immobilization. Moreover, because of the complex structure and multiple types of binding sites of proteins, monotonous binding sites of groups or chains might not satisfy the demands of the protein.

${ }^{a}$ School of Natural and Applied Science, Northwestern Polytechnical University, Xi'an 710072, P. R China. E-mail: huxl054@163.com

${ }^{b}$ College of Chemistry and Chemical Engineering, Xi'an Shiyou University, Xi'an 710065, P. R. China

† Electronic supplementary information (ESI) available. See DOI: 10.1039/c9ra02265a
Therefore, there are great opportunities to design and exploit multi-functional $\mathrm{SiO}_{2}$ to immobilize protein for biomedical applications.

Recently, ionic liquids (ILs) have been regarded as promising "green materials" in various fields, such as electrochemistry, separation chemistry, catalytic chemistry and biological chemistry, due to their excellent properties and wide applications. ${ }^{18,19}$ Because of their abilities in functional design, ILs have been used in many aspects of biomolecules. Our group have utilized an imidazole-based amphiphilic IL, 1-dodecyl-3methylimidazolium chloride as a surfactant to immobilize bovine serum albumin (BSA) in the molecular imprinting process, which exhibited a good stabilization effect on BSA. ${ }^{20}$ Some studies of the application of IL-functionalized materials for biological application are those of Song et al., who prepared an acidic IL-modified $\mathrm{SiO}_{2}$ gel for selective separation of BSA and bovine hemoglobin (BHb). ${ }^{21}$ Subsequently, Qian et al. immobilized BSA on the surface of ionic liquid-functionalized magnetic $\mathrm{Fe}_{3} \mathrm{O}_{4}$ nanoparticles for the development of a surface imprinting strategy. ${ }^{22}$ Therefore, ILs not only could be used directly, but also could be grafted on the surface of nanomaterials for various biological applications. With respect to practicality and facility, the design and construction of ILfunctionalized, modified or grafted nanoparticles is very promising.

In this work, a silane-coupling ionic liquid, 1-(3trimethoxysilylpropyl)-3-methylimidazolium chloride ([TMIM] $\mathrm{Cl}$ ) was first synthesized and grafted onto $\mathrm{SiO}_{2}$ nanoparticles to construct functional $\mathrm{SiO}_{2}$ nanoparticles $\left(\mathrm{SiO}_{2} @ \mathrm{IL}\right)$. Thereafter, the $\mathrm{SiO}_{2} @ \mathrm{IL}$ nanoparticles obtained were applied to the immobilization of BSA by using the multiple binding sites via multiple non-covalent bonds (shown in Scheme 1). To reveal the 


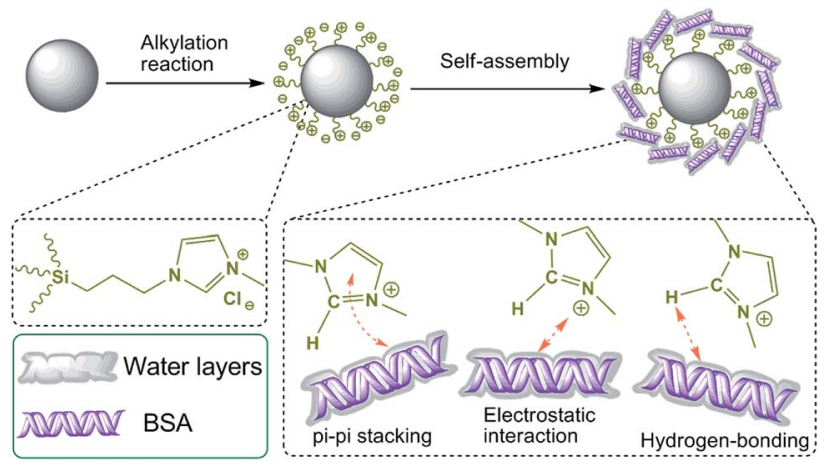

Scheme 1 Schematic diagram of preparation of $\mathrm{SiO}_{2}$ QIIL and BSA bound onto the surface of $\mathrm{SiO}_{2} \mathrm{QlL}$.

binding mechanism, theoretical calculation of density functional theory (DFT) was employed to investigate the multifunctionality of the imidazolium group on the surface of $\mathrm{SiO}_{2} @ \mathrm{IL}$. The nanoparticles were well characterized to monitor every step of processing. Subsequently, the adsorption equilibrium, kinetics and stability of $\mathrm{SiO}_{2} @ I L$ for BSA immobilization were investigated.

\section{Experimental}

\section{Materials}

$N$-Methylimidazole (MI, Shanghai Dibo Chemical Technology Co., Ltd), $\gamma$-chloropropyl(trimethoxy)-silane (CPTMO, Aladdin), and benzoquinone (BQ, Aladdin) were used without further purification. Bovine serum albumin (BSA, $M_{\mathrm{w}} 66.4 \mathrm{kDa}$, SigmaAldrich) was used in immobilization studies. Ethyl acetate, tetraethoxysilane (TEOS), ammonium hydroxide, and methylbenzene were purchased from Sinopharm Chemical Reagent Co., Ltd, China.

\section{Characterization}

The morphology, chemical surface characterization, and surface potential of the nanoparticles were characterized by scanning electron microscopy (SEM, FEI Quanta 400 FEG), Xray photoelectron spectroscopy (XPS, Shimadzu) and zeta (५)potential measurement (ZEN3690 Zetasizer Nano detector, Malvern), respectively. The concentration of BSA in the adsorption experiments was detected using a UV-2550 (Shimadzu) spectrophotometer at $277 \mathrm{~nm}$.

\section{Synthesis of [TMIM]Cl}

[TMIM]Cl was synthesized by a one-step alkylation reaction. ${ }^{23,24}$ Typically, CPTMO (10.06 mL), MI ( $5.00 \mathrm{~mL})$ and BQ $(52 \mathrm{mg})$ were dispersed together and the mixture was treated ultrasonically to form the homogeneous solution. After exposure to nitrogen purge for $30 \mathrm{~min}$, the solution was placed in a water bath for $72 \mathrm{~h}$ at $80^{\circ} \mathrm{C}$. After that, the crude fluid was washed with ethyl acetate four times and dried under vacuum at $55{ }^{\circ} \mathrm{C}$ for $48 \mathrm{~h}$ to obtain the pure product with a dark brown color.

\section{Preparation and functionalization of $\mathrm{SiO}_{2}$ nanoparticles}

$\mathrm{SiO}_{2}$ nanoparticles were prepared using the method reported by Stöber. ${ }^{25}$ Typically, ammonium hydroxide $(27 \mathrm{~mL})$, ethyl alcohol $(48.75 \mathrm{~mL})$ and distilled water $(74.25 \mathrm{~mL})$ were mixed together. Then TEOS $(13.5 \mathrm{~mL})$ and ethyl alcohol $(136.5 \mathrm{~mL})$ were added into the mixture rapidly under vigorous stirring for $2 \mathrm{~h}$ at $25^{\circ} \mathrm{C}$. After the reaction, the white product was washed with ethyl alcohol and distilled water by centrifugal separation, respectively. Then the obtained $\mathrm{SiO}_{2}$ nanoparticles were dried under $45{ }^{\circ} \mathrm{C}$ until the weight remained constant.

The functionalization of $\mathrm{SiO}_{2}$ was conducted as follows. [TMIM] Cl (0.7 g), ethyl alcohol $(10 \mathrm{~mL})$ and methylbenzene (40 $\mathrm{mL}$ ) were mixed together to form the homogeneous solution. Then the obtained $\mathrm{SiO}_{2}$ nanoparticles $(0.6 \mathrm{~g})$ were added to the above solution and kept at $50{ }^{\circ} \mathrm{C}$ for $8 \mathrm{~h}$ under nitrogen. After the reaction, the obtained $\mathrm{SiO}_{2} @ \mathrm{IL}$ was washed with ethyl alcohol by centrifugation at $6500 \mathrm{rpm}$ for $6 \mathrm{~min}$ and dried under vacuum at $40{ }^{\circ} \mathrm{C}$ for $24 \mathrm{~h}$.

\section{Adsorption and elution experiments}

$\mathrm{SiO}_{2} @ I L$ nanoparticles $(10 \mathrm{mg})$ were first washed once using phosphate buffer saline (PBS, $0.01 \mathrm{M}$ ) and BSA solution (PBS, 10 $\mathrm{mL}, \mathrm{pH}=7.0$ ) added to certain concentrations. The mixture was stirred at $200 \mathrm{rpm}$ for $24 \mathrm{~h}$ at $25{ }^{\circ} \mathrm{C}$ to facilitate adsorption of non-covalent self-assembly BSA with $\mathrm{SiO}_{2} @ I L$. Then, the nanoparticles were washed with deionized water until no BSA was detected using the UV-2550 spectrophotometer at $277.0 \mathrm{~nm}$ detection wavelength.

The immobilization capacity $\left(Q_{\mathrm{e}}\right)$ of the nanoparticles for BSA was calculated using the following equation:

$$
Q_{\mathrm{e}}\left(\mathrm{mg} \mathrm{g}^{-1}\right)=\frac{\left(C_{0}-C_{\mathrm{e}}\right) V}{m}
$$

where $C_{0}$ is the concentration of BSA solution $\left(\mathrm{mg} \mathrm{mL}^{-1}\right)$ at the initial state, $C_{\mathrm{e}}$ is the BSA concentration of the equilibrium solution $\left(\mathrm{mg} \mathrm{mL}^{-1}\right), V$ is the volume of BSA solution $(\mathrm{mL})$ and $m$ is the mass $(\mathrm{g})$ of BSA.

The nanoparticles were washed for a few cycles with a solution containing acetic acid $(10 \%, \mathrm{v} / \mathrm{v})$ and purified water. The complete removal of BSA was confirmed using the UV-2550 spectrophotometer.

\section{Theoretical calculation}

To investigate the multiple binding mechanisms of imidazolium groups for biomolecules, DFT at B3LYP/6-311+G (d, p) level using Gaussian 16 was used to calculate the binding energies of imidazolium and the special groups of BSA..$^{26,27}$ Here, the value of BSSE was ignored because of the large basis sets used in this work. ${ }^{28}$ Therefore, the binding strength could be described by the binding energy $\Delta E$, and $\Delta E$ for each compound can be obtained via eqn (2) as follows:

$$
\begin{aligned}
\Delta E= & \Delta E(\text { imidazolium group of BSA })-[\Delta E(\text { imidazolium }) \\
& +\Delta E(\text { group of BSA })]
\end{aligned}
$$


where $\Delta E$ (imidazolium group of BSA) is the electronic energy of the compound with the polarized continuum model (PCM), $\Delta E$ (imidazolium) is the electronic energy of the imidazolium with the PCM, and $\triangle E$ (group of BSA) is the electronic energy of the special/specific functional group of BSA with the PCM.

\section{Results and discussion}

\section{Synthesis of [TMIM]Cl}

The successful synthesis of [TMIM] $\mathrm{Cl}\left(\mathrm{C}_{10} \mathrm{SiO}_{3} \mathrm{~N}_{2} \mathrm{ClH}_{21}\right)$ was characterized by using Fourier-transform-infrared (FTIR) and ${ }^{1}$ H NMR spectroscopy. As shown in Fig. S1, $\dagger$ typical characteristic peaks were found at 1548 and $1454 \mathrm{~cm}^{-1}$, which were assigned to the stretching vibration of the imidazolium groups. Moreover, the typical peaks of $\mathrm{C}=\mathrm{N}, \mathrm{Si}-\mathrm{O}$ and $\mathrm{Si}-\mathrm{C}$ stretching vibrations could be seen at $1654,810 / 1055$ and $1240 / 1410 \mathrm{~cm}^{-1}$, respectively. In order to confirm the synthesis of [TMIM]Cl accurately, the ${ }^{1} \mathrm{H}$ NMR spectrum was acquired. As shown in Fig. S2, $\dagger$ the chemical shifts were at $8.86(1 \mathrm{H}, \mathrm{s}), 7.67(1 \mathrm{H}, \mathrm{s})$, $6.82(1 \mathrm{H}, \mathrm{s}), 4.39(2 \mathrm{H}, \mathrm{t}), 3.89(3 \mathrm{H}, \mathrm{s}), 3.16(9 \mathrm{H}, \mathrm{m}), 1.59(2 \mathrm{H}, \mathrm{m})$ and $0.67(2 \mathrm{H}, \mathrm{m})$, respectively. Due to the fact that the reactants could be washed with the solvent ethyl acetate, and that ethyl acetate was easily removed under vacuum, the obtained product was relatively pure. For the IL-functionalization of $\mathrm{SiO}_{2}$ in this work, the obtained product could meet requirements because some subsequent washing procedures were conducted repeatedly, which undoubtedly eluted the reactants.

\section{Preparation of $\mathrm{SiO}_{2}$ nanoparticles}

The morphological features of the $\mathrm{SiO}_{2}$ nanoparticles were first observed using SEM. Fig. 1a and b show that the $\mathrm{SiO}_{2}$ nanoparticles are spherical in shape and exhibit a relatively uniform morphology. Moreover, the average size of the $\mathrm{SiO}_{2}$ nanoparticles was obtained by dynamic light scattering (Fig. 1c), and the results established that the average size of the $\mathrm{SiO}_{2}$ nanoparticles was about $350 \mathrm{~nm}$, with a narrow size distribution. In addition, XPS was performed to characterize the surface chemical composition of $\mathrm{SiO}_{2}$ nanoparticles using Gaussian and Lorentzian curve fitting. ${ }^{29}$ Fig. $1 \mathrm{~d}$ demonstrates that the $\mathrm{SiO}_{2}$ nanoparticles consisted of $\mathrm{C}, \mathrm{O}$ and $\mathrm{Si}$, with the atomic compositions of $\mathrm{C}, \mathrm{O}$ and $\mathrm{Si}$ calculated as 63.2, 27.5 and 9.3 atom $\%$, respectively.

\section{Ionic liquid functionalization of $\mathrm{SiO}_{2}$ nanoparticles}

In order to determine the surface functionalization of $\mathrm{SiO}_{2}$ nanoparticles, XPS was also employed to investigate the surface elements and chemical composition. As shown in Fig. 1d, $\mathrm{SiO}_{2} @ \mathrm{IL}$ consisted of $\mathrm{C}, \mathrm{O}, \mathrm{Si}, \mathrm{N}$ and $\mathrm{Cl}$, which were calculated with compositions of $61.7,25.4,8.2,3.9$ and 0.8 atom\%, respectively. Fig. 1e shows that there were two peaks at 400.6 and $398.5 \mathrm{eV}$ in $\mathrm{N} 1 \mathrm{~s}$, which was assigned as the $\mathrm{N}$ of the imidazolium groups. In addition, Fig. If shows that only one component of $\mathrm{Cl} 2 \mathrm{p}\left(\mathrm{Cl} 2 \mathrm{p}^{3 / 2}\right.$ and $\left.\mathrm{Cl} 2 \mathrm{p}^{1 / 2}\right)$ existed after deconvolution. This binding energy of $\mathrm{Cl} 2 \mathrm{p}^{3 / 2}$ showed that it was solely associated with $\mathrm{Cl}^{-}$which was in good agreement with the reference. ${ }^{30}$ According to analysis of the XPS results, it was
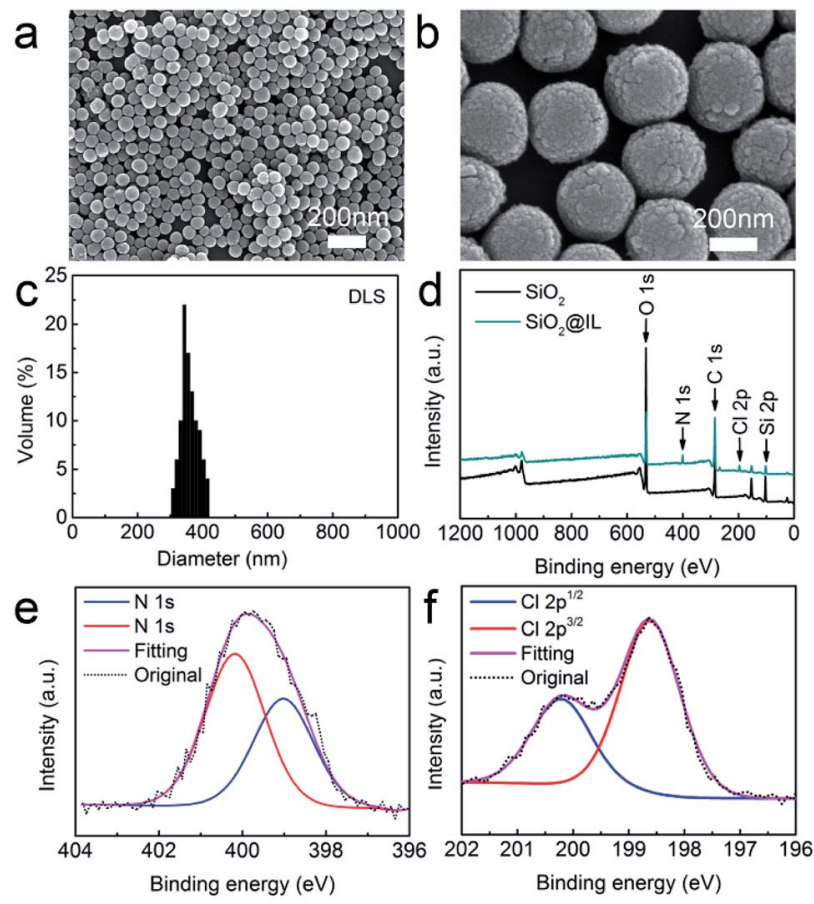

Fig. 1 (a) SEM images of $\mathrm{SiO}_{2}$ nanoparticles. (b) $\mathrm{SEM}$ images of $\mathrm{SiO}_{2}$ nanoparticles at high resolution. (c) DLS size distribution of $\mathrm{SiO}_{2}$ nanoparticles. (d) XPS survey spectra of $\mathrm{SiO}_{2}$ nanoparticles and $\mathrm{SiO}_{2}$ alL. (e) $\mathrm{N}$ 1s XPS spectra of $\mathrm{SiO}_{2}$ (all. (f) $\mathrm{Cl} 2 \mathrm{p}$ XPS spectra of $\mathrm{SiO}_{2}$ alt.

confirmed that the ionic liquid functionalization of $\mathrm{SiO}_{2} @ \mathrm{IL}$ had been carried out successfully.

\section{Batching isotherm}

The adsorption isotherm experiments of $\mathrm{SiO}_{2} @ \mathrm{IL}$ were conducted with BSA concentrations in the range $0.20-1.60 \mathrm{mg}$ $\mathrm{mL}^{-1}$ ( $\left.\mathrm{pH} 7.0, \mathrm{PBS}\right)$ to confirm the superiority of the properties of the ionic liquid. As shown in Fig. 2a, the immobilization capacity of $\mathrm{SiO}_{2} @ \mathrm{IL}$ for BSA increased with the initial concentration of BSA in the range $0.20-0.80 \mathrm{mg} \mathrm{mL}^{-1}$. In addition, a stable immobilization capacity of $23.1 \mathrm{mg} \mathrm{g}^{-1}$ was obtained with the increasing of the concentration of BSA from $0.80 \mathrm{mg}$ $\mathrm{mL}^{-1}$. As for $\mathrm{SiO}_{2}$, the immobilization capacity was always at a low value, indicating that the functional groups on the surface of $\mathrm{SiO}_{2} @ I L$ could facilitate the binding of $\mathrm{SiO}_{2} @ I L$ for BSA. The maximum immobilization capacity of $\mathrm{SiO}_{2} @ \mathrm{IL}$ for BSA was improved more than tenfold. In PBS with $\mathrm{pH} 7.0$, the functional groups and imidazolium groups could be ionized and form multiple binding sites with BSA. Considering BSA with a pI of 4.7, it was easier for imidazolium groups to bind BSA. For unmodified $\mathrm{SiO}_{2}$, only a very small amount of hydroxyl groups existed, so it was very difficult for $\mathrm{SiO}_{2}$ to bind BSA.

In addition, Langmuir and Freundlich isotherm models were performed to investigate the adsorption mechanism of $\mathrm{SiO}_{2} @ I L$ for BSA as follows: ${ }^{31}$

$$
\frac{C_{\mathrm{e}}}{Q_{\mathrm{e}}}=\frac{C_{\mathrm{e}}}{Q_{\max }}+\frac{1}{K_{\mathrm{L}} Q_{\max }}
$$



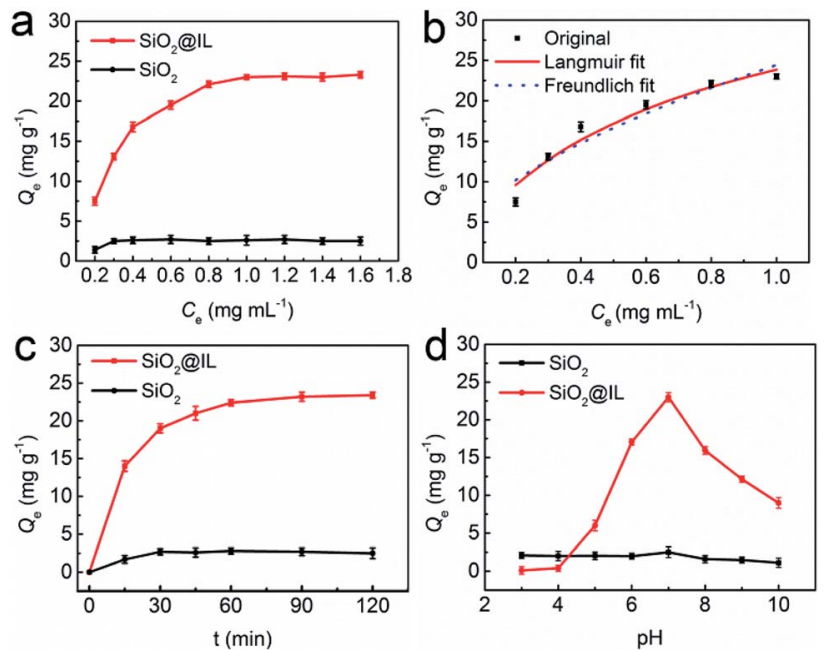

Fig. 2 (a) Immobilization capacity of $\mathrm{SiO}_{2}$ alL and $\mathrm{SiO}_{2}$ for $\mathrm{BSA}$. (b) Adsorption isotherm curves of $\mathrm{SiO}_{2}$ (aIL for BSA. (c) Adsorption kinetic curves of $\mathrm{SiO}_{2} \mathrm{QIL}$ and $\mathrm{SiO}_{2}$. (d) Effect of pH on immobilization capacity of $\mathrm{SiO}_{2} \mathrm{alL}$ and $\mathrm{SiO}_{2}$ for BSA.

$$
Q_{\mathrm{e}}=K_{\mathrm{F}} C_{\mathrm{e}}^{1 / n}
$$

where $Q_{\mathrm{e}}\left(\mathrm{mg} \mathrm{g}^{-1}\right)$ is the experimental immobilization capacity of $\mathrm{SiO}_{2} @ I L$ for BSA, $Q_{\max }\left(\mathrm{mg} \mathrm{g}^{-1}\right)$ is the theoretical maximum immobilization capacity, $C_{\mathrm{e}}\left(\mathrm{mg} \mathrm{mL}^{-1}\right)$ is the concentration of BSA in equilibrium solution, $K_{\mathrm{L}}\left(\mathrm{L} \mathrm{mg}^{-1}\right)$ is the Langmuir adsorption constant, and $K_{\mathrm{F}}\left(\mathrm{mg} \mathrm{g}^{-1}\right)$ and $n$ are the Freundlich adsorption equilibrium constants.

Fig. 2b shows the Langmuir and Freundlich adsorption equilibrium tendency of $\mathrm{SiO}_{2} @ I L$ for BSA. According to the correlation coefficients $\left(R^{2}\right)$, the Langmuir isotherm model $\left(R^{2}\right.$ $=0.9822$ ) was found to be more suitable than the Freundlich model $\left(R^{2}=0.9182\right)$ for revealing the binding mechanism of $\mathrm{SiO}_{2}$ @IL for BSA, indicating that the binding was uniform with a maximal immobilization capacity $Q_{\mathrm{m}}$ of $37.9 \mathrm{mg} \mathrm{g}^{-1}$, that is, there was only one kind of binding site on the surface of $\mathrm{SiO}_{2} @ I L$. It should be noted that one kind of binding site does not mean one type of interaction. Multiple interactions behaving synergistically could be regarded as one kind of binding site, which will be revealed clearly in the following quantum calculation. From another point of view, the ionic liquid functionalization on the surface of $\mathrm{SiO}_{2}$ nanoparticles was homogeneous, leading to the uniform properties of the surface.

\section{Rebinding kinetics study}

Here, the adsorption dynamics of $\mathrm{SiO}_{2} @ \mathrm{IL}$ and $\mathrm{SiO}_{2}$ for $\mathrm{BSA}$ were investigated. As shown in Fig. 2c, there was a rapid increase of adsorption rate on $\mathrm{SiO}_{2} @ \mathrm{IL}$ for $\mathrm{BSA}$ in the first $30 \mathrm{~min}$ and then the adsorption rate slowed down from $30 \mathrm{~min}$ to $2 \mathrm{~h}$. After about $1 \mathrm{~h}$, adsorption equilibrium was achieved, which indicated that BSA could reach the binding sites of $\mathrm{SiO}_{2}$ @IL easily and quickly. The large number of multiple binding sites provided by the imidazolium groups of $\mathrm{SiO}_{2} @ \mathrm{IL}$ could attract the functional groups of BSA, which induced the rapid binding of BSA. Moreover, the binding sites of $\mathrm{SiO}_{2}$ @IL for BSA were all on the surface of the $\mathrm{SiO}_{2} @ I L$, which could also endow lower mass-transfer resistance. Compared with the low affinity of $\mathrm{SiO}_{2}$ for BSA, the results confirmed that the functionalized $\mathrm{SiO}_{2}$ with the properties of the ionic liquid in this work could exhibit high affinity and rapid adsorption rate because of the driving force of multiple binding sites on the surface.

\section{Effect of $\mathbf{p H}$ on immobilization capacity}

Since the pI of BSA is 4.7, the net charge of BSA in PBS would vary with different $\mathrm{pH}$, because the functional groups, the imidazolium groups, which possess the ionization property, and the immobilization capacity of $\mathrm{SiO}_{2} @ \mathrm{IL}$ for BSA can be affected by $\mathrm{pH}$. Therefore, the immobilization capacity of $\mathrm{SiO}_{2} @ \mathrm{IL}$ for BSA was investigated by changing the pH of PBS.

As shown in Fig. 2d, the immobilization capacity of $\mathrm{SiO}_{2} @ \mathrm{IL}$ for BSA increased at first and then decreased, with increase in $\mathrm{pH}$. The maximum immobilization capacity $\left(Q_{\mathrm{e}}=23.1 \mathrm{mg} \mathrm{g}^{-1}\right)$ was obtained with $\mathrm{pH}$ 7.0. Under $\mathrm{pH}$ 4.0, the net charge of BSA was positive. As a result, it might not be easy for $\mathrm{SiO}_{2} @ I L$ with positive imidazolium groups to bind BSA due to electronic repulsion. On the other hand, when the pH of PBS was higher than 7.0, it should be helpful for $\mathrm{SiO}_{2} @ I L$ to bind BSA, and the immobilization capacity should be higher than that in PBS with a pH of 7.0. However, the immobilization capacity decreased, which might be owing to the following reasons. The decreased immobilization capacities of $\mathrm{SiO}_{2} @ \mathrm{IL}$ for $\mathrm{BSA}$ at $\mathrm{pH}$ of 8 and 9 were most likely due to the change in binding sites, which were not as strong as those at $\mathrm{pH} 7$. When the $\mathrm{pH}$ is set at 10 , the unfolding of BSA might be responsible for the decrease of immobilization capacity of $\mathrm{SiO}_{2} @ I L$ for $\mathrm{BSA}$ for the above reason. ${ }^{32}$ That is to say, the redistributed binding sites were unfavorable for binding on the surface of $\mathrm{SiO}_{2} @ \mathrm{IL}$, which would induce the result of a low immobilization capacity of $\mathrm{SiO}_{2} @ \mathrm{IL}$ for BSA. It should be noted that the other non-covalent bonds would also induce binding of $\mathrm{SiO}_{2} @ \mathrm{IL}$ for BSA. As for $\mathrm{SiO}_{2}$, because of the simple binding sites with hydroxyl groups, it was easy to come to the conclusion that the weak binding affinity of $\mathrm{SiO}_{2}$ would not be affected significantly by $\mathrm{pH}$.

\section{Surface charge properties of $\mathrm{SiO}_{2} @ I L$ for binding BSA}

$\zeta$-Potential is a very effective measurement to study the surface charge properties of nanoparticles in solution. In order to reveal the effect of net charge on the surface of $\mathrm{SiO}_{2} @ \mathrm{IL}$ for BSA, $\zeta$ potential measurements were conducted by choosing a $\mathrm{pH}$ of 4.0, 5.0, 6.0, 7.0 and 8.0. As shown in Table 1, with increase in $\mathrm{pH}$, the $\zeta$-potential value of the surface of $\mathrm{SiO}_{2}$ and $\mathrm{SiO}_{2} @ \mathrm{IL}$ in PBS is reduced, indicating that the surface properties of $\mathrm{SiO}_{2}$ and $\mathrm{SiO}_{2} @ \mathrm{IL}$ could be controlled by the proton concentration. In other words, the adsorption properties of $\mathrm{SiO}_{2}$ and $\mathrm{SiO}_{2} @ \mathrm{IL}$ for BSA were affected by $\mathrm{pH}$. Some typical results have shown that electrostatic interaction was the important driving force for the adsorption, especially for the $\mathrm{SiO}_{2}$-based nanoparticles. ${ }^{33,34}$ Due to the differences in the $\mathrm{pH}$ environment and the change in 
Table 1 ל-Potential of $\mathrm{SiO}_{2} \mathrm{alL}$ and $\mathrm{SiO}_{2}$ in PBS with different pH

\begin{tabular}{lcc}
\hline Sample & $\mathrm{pH}$ & $\zeta$-Potential $(\mathrm{mV})$ \\
\hline $\mathrm{SiO}_{2} @ \mathrm{IL}$ & 4.0 & $35.2 \pm 1.1$ \\
& 5.0 & $32.8 \pm 0.9$ \\
& 6.0 & $23.6 \pm 1.8$ \\
& 7.0 & $25.7 \pm 0.3$ \\
$\mathrm{SiO}_{2}$ & 8.0 & $8.4 \pm 0.7$ \\
& 4.0 & $0.6 \pm 0.6$ \\
& 5.0 & $-4.1 \pm 0.5$ \\
& 6.0 & $-29.7 \pm 0.3$ \\
& 7.0 & $-42.2 \pm 0.4$ \\
& 8.0 & $-61.6 \pm 0.7$
\end{tabular}

the secondary structure of BSA at different $\mathrm{pH}(\mathrm{pH}<4$ and $\mathrm{pH}>$ 9), ${ }^{32}$ the binding sites of $\mathrm{SiO}_{2}$ and $\mathrm{SiO}_{2} @ I L$ for BSA would also be different. However, compared with $\mathrm{SiO}_{2}, \mathrm{SiO}_{2} @ I L$ exhibited stronger affinity for BSA under the same $\mathrm{pH}$ environment (Fig. 1d). In other words, it is clear that electrostatic interactions are a very important driving force for biomolecules to be bound to the surface of nanoparticles. ${ }^{35-37}$ Therefore, it is acceptable to construct the nanoparticles with special properties on their surface for binding or immobilizing biomacromolecules.

\section{Binding mechanism of $\mathrm{SiO}_{2} @ I L$ for BSA}

Currently, computer simulation/calculation is often combined with experimental studies to explore detailed interaction mechanisms. In research in molecular simulations, molecular dynamics simulation and quantum mechanics calculations have been applied to different research systems. ${ }^{38,39}$ For systems with more than 500 atoms, it is not easy to calculate their properties by using quantum mechanics simulation. To uncover their role in adsorption on the surface of $\mathrm{SiO}_{2} @ \mathrm{IL}$, we have simplified the models and calculated the binding energies of different functional groups of BSA with the functional groups on the surface of $\mathrm{SiO}_{2} @ \mathrm{IL}$, namely imidazolium groups. For this, various molecules, including $\mathrm{CH}_{3}-\mathrm{X}\left(\mathrm{X}=-\mathrm{OH},-\mathrm{SH},-\mathrm{NH}_{2}\right.$, $-\mathrm{COOH},-\mathrm{SSCH}_{3}$ and $-\mathrm{C}_{6} \mathrm{H}_{5}$ ), were chosen as the models of the functional groups of BSA. ${ }^{40}$ Then, to illustrate the functionality of ionic liquid-based properties on the surface of $\mathrm{SiO}_{2} @ \mathrm{IL}$, firstprinciples calculations based on DFT were performed to evaluate the physical adsorption of BSA on the surface of $\mathrm{SiO}_{2} @ I L$.

Fig. 3 describes the stable conformations of the functional groups of BSA with 1-propyl-3-ethylimidazolium (PEIM), which clearly illustrate the non-covalent bindings of the electron bond donors and electron bond acceptors. It was found that the typically polar atoms $\mathrm{S}, \mathrm{O}$ and $\mathrm{N}$ with lone-pair electrons in Fig. 3a-e were more likely to form non-covalent bonding with the $\mathrm{H}$ of the imidazolium group. As shown in Fig. $3 \mathrm{f}$, an edge-toface $\pi-\pi$ stacking interaction formed between the $\mathrm{H}$ of the imidazolium group and the benzene ring. In the previous discussion, due to the fact that the immobilization capacity of $\mathrm{SiO}_{2} @ I L$ for BSA changed significantly with changing $\mathrm{pH}$, it was quite clear that there were electrostatic interactions between the imidazolium groups and BSA. What is more, Table 2 reveals that the binding energies $(\Delta E)$ of these compounds demonstrated

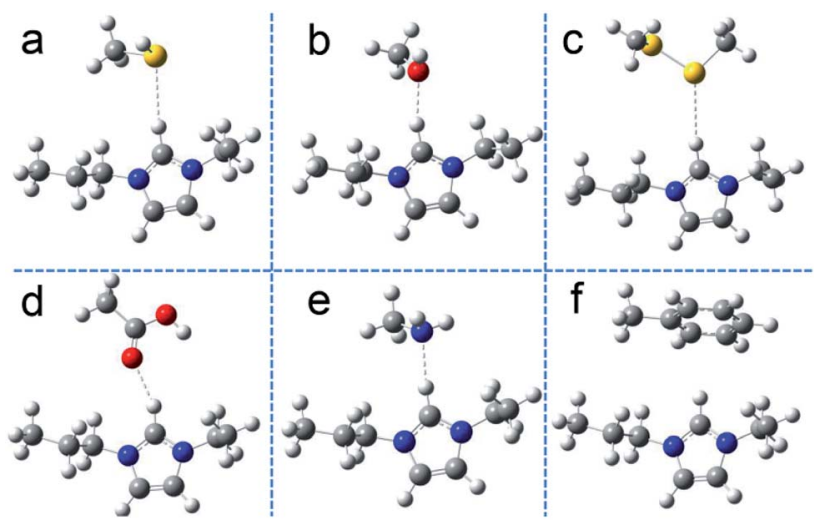

Fig. 3 Hydrogen bonding and $\pi-\pi$ stacking interactions in the complexes of PEIM and models of functional groups of BSA, namely, $\mathrm{CH}_{3}-\mathrm{SH}$ (a), $\mathrm{CH}_{3}-\mathrm{OH}$ (b), $\mathrm{CH}_{3}-\mathrm{SSCH}_{3}$ (c), $\mathrm{CH}_{3}-\mathrm{COOH}$ (d), $\mathrm{CH}_{3}-\mathrm{NH}_{2}$ (e) and $\mathrm{CH}_{3}-\mathrm{C}_{6} \mathrm{H}_{5}$ (f).

some differences, and the $\pi-\pi$ stacking interaction was the weakest non-covalent interaction.

Lipkowski et al. have found that the following criteria could be used to confirm hydrogen bonding and these criteria are universal and essential: existence of bond critical points (BCP), density total $(\rho)$ and Laplacian eigenvalue $\left(\nabla^{2} \rho\right)$ being in the range of approximately $0.002-0.04$ a.u. and $0.02-0.15$ a.u., respectively. ${ }^{41}$ The binding energies and distances are listed in Table 2. To further reveal the specific types of hydrogen binding that exist between $\mathrm{SiO}_{2} @ \mathrm{IL}$ and $\mathrm{BSA}$, demonstrating whether the interactions between electron donors of the functional groups of BSA and electron acceptor of PEIM were hydrogen bonding interactions or not, the atoms-in-molecules (AIM) electron density topological analysis (proposed by Bader et al. ${ }^{42-44}$ ) for these compounds was conducted. Based on the above theory, the topological properties of $\mathrm{BCP}$ for the compounds at MP2/6-311+G(d,p) level was obtained (shown in Table 2). It was found that BCPs existed for $\mathrm{CH}_{3}-\mathrm{OH}$ (in Fig. 3b) and $\mathrm{CH}_{3}-\mathrm{COOH}$ (in Fig. $3 \mathrm{~d}$ ), while no BCP could be formed in the other compounds. As shown in Table 2, both $\rho$ and $\nabla^{2} \rho$ of the compounds PEIM/ $\mathrm{CH}_{3}-\mathrm{OH}$ and PEIM/ $\mathrm{CH}_{3}-\mathrm{COOH}$ were in the range of $0.002-0.04$ a.u. and $0.02-0.15$ a.u., respectively, indicating that there were typical hydrogen-bonding interactions in $\mathrm{PEIM} / \mathrm{CH}_{3}-\mathrm{OH}$ and $\mathrm{PEIM} / \mathrm{CH}_{3}-\mathrm{COOH}$. KubiakOssowska et al. have shown that electrostatics play an

Table 2 Binding energies of the complexes of PEIM and functional groups of BSA, and topological properties of the bond critical points (BCP) of the compounds

\begin{tabular}{lllllll}
\hline Compound & $\begin{array}{l}\Delta E \\
\left(\mathrm{~kJ} \mathrm{~mol}^{-1}\right)\end{array}$ & $\begin{array}{l}\text { Distance } \\
(\AA)\end{array}$ & BCP & $\rho$ & $\nabla^{2} \rho$ \\
\hline \multirow{2}{*}{ PEIM } & $\mathrm{CH}_{3}-\mathrm{SH}$ & -4.1 & 2.751 & 0 & - & - \\
& $\mathrm{CH}_{3}-\mathrm{OH}$ & -10.7 & 2.049 & 1 & 0.01961 & 0.06287 \\
& $\mathrm{CH}_{3}-\mathrm{SSCH}$ & -24.9 & 2.898 & 0 & - & - \\
& $\mathrm{CH}_{3}-\mathrm{COOH}_{3}$ & -7.5 & 2.136 & 1 & 0.01399 & 0.05031 \\
& $\mathrm{CH}_{3}-\mathrm{NH}_{2}$ & -12.6 & 2.129 & 0 & - & - \\
& $\mathrm{CH}_{3}-\mathrm{C}_{6} \mathrm{H}_{5}$ & -1.0 & - & - & - & -
\end{tabular}




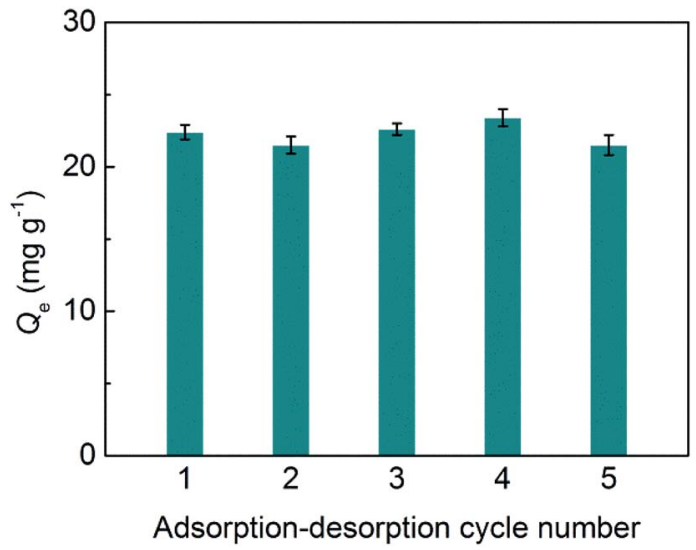

Fig. 4 Stability of $\mathrm{SiO}_{2}$ aIL for binding BSA.

important role in the adsorption of charged protein on $\mathrm{SiO}_{2}$ nanoparticles by atomistic molecular dynamics. ${ }^{45}$ Analogously, electrostatics was also the important driving force for BSA adsorption on the charged $\mathrm{SiO}_{2} @ \mathrm{IL}$. However, multiple interactions commonly exist due to the diversity of biomacromolecules and carriers, including ion-ion electrostatic interactions $\left(20-80 \mathrm{kcal} \mathrm{mol}^{-1}\right)$, coordination bonding (20$50 \mathrm{kcal} \mathrm{mol}^{-1}$ ), hydrogen bonding (1-30 kcal mol${ }^{-1}$ ), $\pi-\pi$ stacking (0-12 kcal mol$\left.{ }^{-1}\right)$, and van der Waals interactions. ${ }^{30,46}$ Combined with the above analysis, it could be confirmed that the adsorption of $\mathrm{SiO}_{2} @ \mathrm{IL}$ was driven by the synergistic interactions of electrostatic interaction, hydrogen bonding and $\pi-\pi$ stacking. The differences between these non-covalent interactions were the probability and binding strength, which obey the Boltzmann distribution. ${ }^{47}$ The non-directional, non-covalent interaction (electrostatic interaction) and directional noncovalent interactions (hydrogen bonding, $\pi-\pi$ stacking) synergistically varied the functionalization of biomacromoleculenanoparticle complexes.

\section{Stability of $\mathrm{SiO}_{2} @ \mathrm{IL}$}

The stability of $\mathrm{SiO}_{2} @ I L$ is critical for its potential applications. Herein, adsorption-desorption tests for $\mathrm{SiO}_{2} @ \mathrm{IL}$ were conducted for five cycles. As shown in Fig. 4, there was almost no change in immobilization capacity of $\mathrm{SiO}_{2} @ \mathrm{IL}$ for BSA after five cycles at $1.0 \mathrm{mg} \mathrm{mL}{ }^{-1}$ of BSA. These results show that the binding sites on the surface of $\mathrm{SiO}_{2} @ \mathrm{IL}$ were very stable. Moreover, due to the grid structure of $\mathrm{SiO}_{2}$, the core of $\mathrm{SiO}_{2} @ \mathrm{IL}$ was also stable, which ensured the stability of $\mathrm{SiO}_{2} @ \mathrm{IL}$. Therefore, $\mathrm{SiO}_{2} @ I L$ possesses the potential for reusability, which lays the foundation for practical applications.

\section{Conclusions}

In this work, a functional nanoparticle with ionic liquid properties was prepared by using a one-step grafting reaction. The obtained $\mathrm{SiO}_{2} @ \mathrm{IL}$ showed good binding ability for BSA and the adsorption experiment and theoretical calculations revealed that the binding of $\mathrm{SiO}_{2} @ \mathrm{IL}$ for BSA was driven by multiple binding interactions, such as electrostatic interactions, hydrogen bonding and $\pi-\pi$ stacking. In particular, it was found that electrostatic interactions were the driving force for $\mathrm{SiO}_{2} @ \mathrm{IL}$ to immobilize BSA. The results reported in this work demonstrate the promising potential for exploring designed nanoparticles with ionic liquid properties for biomacromolecule applications.

\section{Conflicts of interest}

There are no conflicts to declare.

\section{Acknowledgements}

$\mathrm{X}$. Jia and X. Hu are grateful for the financial support provided by the National Natural Science Foundation of China (grant no. 51433008). Moreover, X. Jia, W. Wang and C. Du thank the Modern Analysis and Testing Center of Xi'an Shiyou University.

\section{Notes and references}

1 A. E. Nel, L. Mädler, D. Velegol, T. Xia, E. M. Hoek, P. Somasundaran, F. Klaessig, V. Castranova and M. Thompson, Nat. Mater., 2009, 8, 543-557.

2 M. Mahmoudi, I. Lynch, M. Ejtehadi, M. P. Monopoli, F. Bombelli and S. Laurent, Chem. Rev., 2011, 111, 56105637.

3 D. Li, B. Ji, K. Hwang and Y. Huang, J. Phys. Chem. B, 2016, 114, 3060-3069.

4 Y. Cheng, L.-D. Koh, F. Wang, D. Li, B. Ji, J. Yeo, G. Guan, M. Han and Y.-W. Zhang, Nanoscale, 2017, 9, 9181-9189.

5 Z. Li, H. Yin, Z. Zhang, K. L. Liu and J. Li, Biomacromolecules, 2012, 13, 3162-3172.

6 L. Shang and G. U. Nienhaus, Mater. Today, 2013, 16, 58-66.

7 Z. Li and X. J. Loh, Chem. Soc. Rev., 2015, 44, 2865-2879.

8 Y. Min, J. M. Caster, M. J. Eblan and A. Z. Wang, Chem. Rev., 2015, 115, 11147-11190.

9 C. Du and B. Han, Acta Phys.-Chim. Sin., 2019, DOI: 10.3866/ PKU.WHXB201905058.

10 C. Du, X. Hu, G. Zhang and Y. Cheng, Acta Phys.-Chim. Sin., 2019, DOI: 10.3866/PKU.WHXB201812057.

11 N. P. King, W. Sheffler, M. R. Sawaya, B. S. Vollmar, J. P. Sumida, I. André, T. Gonen, T. O. Yeates and D. Baker, Science, 2012, 336, 1171-1174.

12 C. Y. K. Chan, Z. J. Zhao, J. W. Y. Lam, J. Z. Liu, S. M. Chen, P. Lu, F. Mahtab, X. J. Chen, H. H. Y. Sung, H. S. Kwok, Y. G. Ma, I. D. Williams, K. S. Wong and B. Z. Tang, Adv. Funct. Mater., 2012, 22, 3170-3180.

13 N. P. King, J. B. Bale, W. Sheffler, D. E. McNamara, S. Gonen, T. Gonen, T. O. Yeates and D. Baker, Nature, 2014, 510, 103108.

14 G. Guan, J. Xia, S. Liu, Y. Cheng, S. Bai, S. Y. Tee, Y.-W. Zhang and M. Y. Han, Adv. Mater., 2017, 29, 1700326.

15 M. Madliger, M. Sander and R. P. Schwarzenbach, Environ. Sci. Technol., 2010, 44, 8870-8876.

16 Q. Liu, J. Shi, M. Cheng, G. Li, D. Cao and G. Jiang, Chem. Commun., 2012, 48, 1874-1876. 
17 H. Kim, J. Hong, Y. U. Park, K. Jinsoo, H. Insang and K. Kisuk, Adv. Funct. Mater., 2015, 25, 5823-5832.

18 X. Gao, X. Hu, P. Guan, C. Du, S. Ding, X. Zhang, B. Li, X. Wei and R. Song, RSC Adv., 2016, 6, 110019-110031.

19 A. J. Holding, A. Parviainen, I. Kilpeläinen, A. Soto, A. W. T. King and H. Rodríguez, RSC Adv., 2017, 7, 1745117461.

20 N. Zhang, X. Hu, P. Guan, C. Du, J. Li, L. Qian, X. Zhang, S. Ding and B. Li, Chem. Eng. J., 2017, 317, 356-367.

21 H. Song, C. Yang, A. Yohannes and S. Yao, RSC Adv., 2016, 6, 107452-107462.

22 L. Qian, J. Sun, C. Hou, J. Yang, Y. Li, D. Lei, M. Yang and S. Zhang, Talanta, 2017, 168, 174-182.

23 J. F. P. Liévanoa and L. A. C. Díaz, Mater. Res., 2016, 19, 534541.

24 T. Ishii, T. Enoki, T. Mizumo, J. Ohshita and Y. Kaneko, RSC Adv., 2015, 5, 15226-15232.

25 W. Stöber, A. Fink and E. Bohn, J. Colloid Interface Sci., 1968, 26, 62-69.

26 M. J. Frisch, G. W. Trucks, H. B. Schlegel, G. E. Scuseria, M. A. Robb, J. R. Cheeseman, G. Scalmani, V. Barone, G. A. Petersson, H. Nakatsuji, X. Li, M. Caricato, A. V. Marenich, J. Bloino, B. G. Janesko, R. Gomperts, B. Mennucci, H. P. Hratchian, J. V. Ortiz, A. F. Izmaylov, J. L. Sonnenberg, D. Williams-Young, F. Ding, F. Lipparini, F. Egidi, J. Goings, B. Peng, A. Petrone, T. Henderson, D. Ranasinghe, V. G. Zakrzewski, J. Gao, N. Rega, G. Zheng, W. Liang, M. Hada, M. Ehara, K. Toyota, R. Fukuda, J. Hasegawa, M. Ishida, T. Nakajima, Y. Honda, O. Kitao, H. Nakai, T. Vreven, K. Throssell, J. A. Montgomery Jr, J. E. Peralta, F. Ogliaro, M. J. Bearpark, J. J. Heyd, E. N. Brothers, K. N. Kudin, V. N. Staroverov, T. A. Keith, R. Kobayashi, J. Normand, K. Raghavachari, A. P. Rendell, J. C. Burant, S. S. Iyengar, J. Tomasi, M. Cossi, J. M. Millam, M. Klene, C. Adamo, R. Cammi, J. W. Ochterski, R. L. Martin, K. Morokuma, O. Farkas, J. B. Foresman and D. J. Fox, Gaussian, Inc., Wallingford CT, 2016.

27 X. Cui, W. Cai and X. Shao, RSC Adv., 2016, 6, 105729105736.

28 A. Kowalska-Baron, Comput. Theor. Chem., 2015, 1057, 7-14.
29 C. Du, X. Hu, P. Guan, X. Gao, R. Song, J. Li, L. Qian, N. Zhang and L. Guo, J. Mater. Chem. B, 2016, 4, 1510-1519. 30 C. Du, X. Hu, P. Guan, L. Guo, L. Qian, R. Song, J. Li and C. Wang, J. Mater. Chem. B, 2015, 3, 3044-3053.

31 J. Li, X. Hu, P. Guan, X. Zhang, L. Qian, R. Song, C. Du and C. Wang, RSC Adv., 2015, 5, 62697-62705.

32 K. Kubiak-Ossowska, K. Tokarczyk, B. Jachimska and P. A. Mulheran, J. Phys. Chem. B, 2017, 121, 3975-3986.

33 B. E. Giverns, N. D. Diklich, J. Fiegel and V. H. Gressian, Biointerphases, 2017, 12, $02 \mathrm{D} 404$.

34 B. E. Giverns, E. Wilson and J. Fiegel, Colloids Surf., B, 2019, 179, 374-381.

35 M. Wiśniewska, K. Szewczuk-Karpisz and D. Sternik, J. Therm. Anal. Calorim., 2015, 120, 1355-1364.

36 B. E. Givens, Z. Xu, J. Fiegel and V. H. Grassian, J. Colloid Interface Sci., 2017, 493, 334-341.

37 L. Shang and G. U. Nienhaus, Acc. Chem. Res., 2017, 50, 387395.

38 Y. Cheng, L. Koh, D. Li, B. Ji, Y. Zhang, J. Yeo, G. Guan, M. Y. Han and Y.-W. Zhang, ACS Appl. Mater. Interfaces, 2015, 7, 21787-21796.

39 J. Gao and F. Ding, Angew. Chem., Int. Ed., 2014, 53, 1403114035.

40 G. Guan, S. Zhang, S. Liu, Y. Cai, M. Low, C. P. Teng, I. Y. Phang, Y. Cheng, K. L. Duei, B. M. Srinivasan, Y. Zheng, Y.-W. Zhang and M.-Y. Han, J. Am. Chem. Soc., 2015, 137, 6152-6155.

41 P. Lipkowski, S. J. Grabowski, T. L. Robinson and J. Leszczynski, J. Phys. Chem. A, 2004, 108, 10865-10872.

42 R. W. F. Bader, Chem. Rev., 1991, 91, 893-928.

43 U. Koch and P. L. A. Popelier, J. Phys. Chem., 1995, 99, 97479754.

44 P. L. A. Popelier, J. Phys. Chem. A, 1998, 102, 1873-1878.

45 K. Kubiak-Ossowska, B. Jachimska and P. A. Mulheran, J. Phys. Chem. B, 2016, 120, 10463-10468.

46 J. E. Lofgreen and G. A. Ozin, Chem. Soc. Rev., 2014, 43, 911933.

47 C. Du, X. Hu, Y. Cheng, J. Gao, Y.-W. Zhang, K. Su, Z. Li, N. Zhang, N. Chang and K. Zeng, Mater. Sci. Eng., C, 2018, 83, 169-176. 